\title{
Activity of Boscalid, Fenhexamid, Fluazinam, Fludioxonil, and Vinclozolin on Growth of Sclerotinia minor and S. sclerotiorum and Development of Lettuce Drop
}

\author{
M. E. Matheron, Extension Plant Pathologist and Research Scientist, and M. Porchas, Research Specialist, Univer- \\ sity of Arizona, Yuma Agricultural Center, Yuma 85364
}

\begin{abstract}
Matheron, M. E., and Porchas, M. 2004. Activity of boscalid, fenhexamid, fluazinam, fludioxonil, and vinclozolin on growth of Sclerotinia minor and S. sclerotiorum and development of lettuce drop. Plant Dis. 88:665-668.

Sclerotinia drop is a major disease of lettuce caused by two soilborne fungi, Sclerotinia minor and S. sclerotiorum. Fungicides such as dicloran (Botran), iprodione (Rovral), and vinclozolin (Ronilan) are currently available in the United States to manage this disease. Studies were conducted to investigate the relative effect of some new fungicides, including boscalid, fenhexamid, fluazinam, and fludioxonil, in comparison with vinclozolin, on growth of S. minor and S. sclerotiorum in agar plate tests as well as control of lettuce drop in the field. At a rate of 0.001 $\mu \mathrm{g} / \mathrm{ml}$, all tested compounds only suppressed mycelial growth of either pathogen from 0 to $20 \%$. At $0.01 \mu \mathrm{g} / \mathrm{ml}$, mycelial growth of S. minor was reduced 82 to $84 \%$ by fludioxonil and fluazinam and only 1 to $16 \%$ by boscalid, fenhexamid, and vinclozolin. At the same rate, mycelial growth of $S$. sclerotiorum was reduced $78 \%$ by fluazinam and from 0 to $12 \%$ by boscalid, fludioxonil, fenhexamid, and vinclozolin. At $0.1 \mu \mathrm{g} / \mathrm{ml}$, all tested chemistries except vinclozolin inhibited mycelial growth of $S$. minor from 70 to $98 \%$, whereas growth of S. sclerotiorum was suppressed 95 to $99 \%$ by fludioxonil and fluazinam, significantly less (40 to $47 \%$ ) by boscalid and fenhexamid, and not at all by vinclozolin. At a rate of $1.0 \mu \mathrm{g} / \mathrm{ml}$, all tested fungicides reduced mycelial growth of S. minor and S. sclerotiorum from 87 to $100 \%$ and 77 to $100 \%$, respectively. Mycelial growth emerging from sclerotia of $S$. minor was reduced from 98 to $100 \%$ by all fungicides tested at a rate of $1.0 \mu \mathrm{g} / \mathrm{ml}$, whereas growth from sclerotia of $S$. sclerotiorum was suppressed from 90 to $96 \%$ by fenhexamid, fludioxonil, fluazinam, and vinclozolin. In lettuce plots infested with S. minor, boscalid and fluazinam provided the highest level of disease control, significantly greater than that achieved with fenhexamid, fludioxonil, and vinclozolin. In the presence of S. sclerotiorum, the highest degree of disease suppression occurred with application of fluazinam, fludioxonil, and vinclozolin, whereas the least effective compound was fenhexamid. Boscalid and fluazinam were more effective against lettuce drop caused by S. minor than disease caused by S. sclerotiorum.
\end{abstract}

Additional keywords: fungicide efficacy, plant disease management

Sclerotinia drop is a major disease of lettuce (Lactuca sativa L.) (2) and can be caused by the soilborne fungi Sclerotinia minor Jagger and S. sclerotiorum (Lib.) de Bary. The disease was first reported in Arizona (3) in 1925 and occurs every year in Yuma County, where approximately $85 \%$ of the 16,000 ha of lettuce produced in Arizona is grown. The lettuce production season in this region typically begins with first seedling in late August and ends the following year with last harvest about midApril. Lettuce drop can appear as early as November; however, disease incidence and severity are greatest from December to March, especially if cool, wet periods occur that favor disease development (2).

Corresponding author: M. E. Matheron

E-mail: matheron@ag.arizona.edu

Accepted for publication 9 February 2004.

Publication no. D-2004-0412-01R

(c) 2004 The American Phytopathological Society
Production of apothecia from sclerotia of $S$. minor is a very rare event; therefore, infections are caused by eruptive germination of sclerotia (17). Mycelium from a single sclerotium can infect and kill a lettuce plant (9). Sclerotia further than $2 \mathrm{~cm}$ from the root usually cannot initiate infections, and those deeper than $8 \mathrm{~cm}$ do not germinate (9). In contrast, sclerotia of $S$. sclerotiorum commonly germinate carpogenically, i.e., by producing an apothecium and ascospores. Such germination is favored by the following conditions: sclerotia located 2 to $3 \mathrm{~cm}$ below the soil surface, temperatures ranging from 11 to $20^{\circ} \mathrm{C}$, and soil matric potentials of -0.03 to $-0.07 \mathrm{MPa}(8,17)$. In our field trials, infection of lettuce by sclerotia of S. sclerotiorum occurred by eruptive germination. In Arizona, infection of lettuce plants in commercial fields by ascospores of $S$. sclerotiorum does occur; however, infection arising from eruptive germination is common, possibly due in part to the infrequent occurrence of prolonged wet periods where soil mois- ture is near saturation at the $2-$ to $3-\mathrm{cm}$ depth.

The efficacy of the fungicides dicloran, iprodione, and vinclozolin for control of Sclerotinia species on lettuce has been documented in earlier research $(12,13,16)$, as well as by extensive use in the field. In Arizona, application of fungicides immediately after thinning and cultivation, at the three- to four-leaf stage, can significantly reduce the incidence of lettuce drop caused by $S$. minor and $S$. sclerotiorum. Recently, some new fungicides have emerged that have activity on Sclerotinia spp. Boscalid has demonstrated efficacy in suppression of diseases caused by $S$. sclerotiorum, such as Sclerotinia stem rot on canola (7) and white mold on snap bean (4). Fenhexamid provided significant reduction of white mold on a Brussels sprouts seed crop, also caused by S. sclerotiorum (5). Fluazinam has provided significant control of Sclerotinia blight on peanut, caused by $S$. minor $(14,15)$, and Sclerotinia stem rot on canola, caused by $S$. sclerotiorum (7). In field studies, fludioxonil reduced sclerotia formation from soybean seed infected with $S$. sclerotiorum by more than $98 \%$ (11).

Vinclozolin has served as an industry standard for management of lettuce drop in Arizona for many years; however, registration for use on lettuce in the United States will soon be canceled. Furthermore, growers desire a higher level of disease control than that provided by fungicides currently available. During 10 yearly fungicide trials conducted at the University of Arizona, Yuma Agricultural Center, the average reduction of lettuce drop caused by $S$. minor and $S$. sclerotiorum when treated at labeled rates was 41 and 58\%, respectively, for vinclozolin and 46 and $38 \%$, respectively, for iprodione, the two primary fungicides used to manage lettuce drop in Arizona.

The objectives of this study were to evaluate four new fungicides along with vinclozolin with respect to inhibition of mycelial growth of $S$. minor and $S$. sclerotiorum as well as disease control in lettuce fields infested with either pathogen. Quantitative in vitro evaluation of fungicide efficacy provides baseline sensitivity data that can be used to monitor potential development of insensitivity to fungicides and may aid in the selection of the most effective compounds for subsequent fungicide screening in the field. 


\section{MATERIALS AND METHODS}

Fungi and fungicides. Sclerotia of $S$. minor and S. sclerotiorum were collected from naturally infected lettuce plants at two different locations in Yuma County. Sclerotia of $S$. minor are relatively small ( 0.5 to $2 \mathrm{~mm}$ in diameter) compared with those of S. sclerotiorum (2 to 20 by 3 to 7 $\mathrm{mm})$. Sclerotia were surface-sterilized by agitation in a $0.5 \%$ solution of $\mathrm{NaClO}(1: 9$ dilution of household bleach) for $3 \mathrm{~min}$, rinsed in sterile distilled water, then plated onto potato dextrose agar (PDA) within plastic petri dishes (9 $\mathrm{cm}$ diameter). One actively growing colony arising from a sclerotium of $S$. minor or S. sclerotiorum was chosen at random and designated SM or SS. These two isolates were used in all subsequent in vitro and field tests. The product name, formulation, and source of each tested fungicide is listed in Table 1.

Growth from mycelial disks. To assess the effect of each fungicide on mycelial growth of $S$. minor and $S$. sclerotiorum, a 6-mm-diameter agar disk from the margin of an actively growing culture of each pathogen was placed at the edge of a series of plastic petri dishes $(9 \mathrm{~cm}$ diameter) containing PDA amended with a test fungicide at concentrations of 0.001, 0.01, 0.1, 0.5 , and $1 \mu \mathrm{g}$ a.i./ml. Fungicides were added to PDA after autoclaving when the agar had cooled to approximately $50^{\circ} \mathrm{C}$. Control petri dishes only contained PDA. Four replicate dishes of each fungicide concentration as well as controls were prepared for each species of Sclerotinia. After a 3-day incubation period at $20^{\circ} \mathrm{C}$ in darkness, the radial growth of mycelia was measured. This test was performed twice.

Growth from sclerotia. Sclerotia used in these experiments were produced from the isolates of $S$. minor and S. sclerotiorum described earlier. Substrate for production of sclerotia of $S$. minor was prepared by placing 15 to 20 cubes of potato tuber tissue (each $1.0 \mathrm{~cm}^{3}$ ) in a series of $125-\mathrm{ml}$ flasks, which were then autoclaved for 20 min, allowed to cool to room temperature for $24 \mathrm{~h}$, then autoclaved again. After autoclaving, the potato tuber tissue within each flask was inoculated with a mycelial disk from an actively growing culture of $S$. minor on PDA. After incubation for 4 weeks at $20^{\circ} \mathrm{C}$ in darkness, mature sclerotia were separated from residual potato tuber tissue by washing the contents of each flask in running water within a soil sieve with a mesh opening of $0.5 \mathrm{~mm}$. Sclerotia were air-dried and stored at room temperature $\left(25^{\circ} \mathrm{C}\right)$ in the laboratory until needed. The substrate for producing sclerotia of $S$. sclerotiorum was prepared by boiling $5.5 \mathrm{~kg}$ of barley grain in 15 liters of tap water for $90 \mathrm{~min}$. After boiling, the liquid was discarded and $1,000 \mathrm{~cm}^{3}$ of moist grain was placed into each of a series of 2-liter widemouth flasks. Flasks were autoclaved for $60 \mathrm{~min}$, allowed to cool to room temperature $\left(25^{\circ} \mathrm{C}\right)$, then autoclaved again $24 \mathrm{~h}$ later. When flasks were cool, the contents of each flask were inoculated with a mycelial disk from an actively growing culture of $S$. sclerotiorum on PDA. After a 6-week incubation period at $20^{\circ} \mathrm{C}$ in darkness, abundant sclerotia had formed. The contents of each container were removed, spread on a clean surface, and air-dried. Sclerotia were collected from the barley seed substrate and stored at room temperature. To evaluate the effect of each fungicide on sclerotium germination and subsequent mycelial growth, sclerotia of $S$. minor and S. sclerotiorum were surface-sterilized in $0.5 \% \mathrm{NaOCl}$ for $3 \mathrm{~min}$, rinsed three times by agitating in $100-\mathrm{ml}$ aliquots of sterile-distilled water, placed on sterile paper towels to absorb excess moisture, then positioned at the edge of a series of plastic petri dishes (9 $\mathrm{cm}$ diameter) containing PDA amended with a test fungicide at concentrations of $0.1,0.5$, and 1 $\mu \mathrm{g}$ a.i./ml. Petri dishes containing fungicides were prepared as described earlier. Five replicate dishes containing each concentration of fungicide as well as controls were prepared for each species of Sclerotinia. After a 5-day incubation period at $20^{\circ} \mathrm{C}$ in darkness, the radial growth of mycelia was measured. This test was performed twice.

Field experiments. Three field trials in artificially infested soils were conducted from 1999 to 2001. Production of sclerotia inoculum for infestation of field plots was described earlier. Lettuce (cv. Winterhaven) was seeded and irrigated the first week of November at the Yuma Agricultural Center in double rows, $30 \mathrm{~cm}$ apart, on beds with $102 \mathrm{~cm}$ between bed centers. After thinning at the three- to four-leaf stage to a $30-\mathrm{cm}$ spacing within each row,
$3.6 \mathrm{~g}$ of sclerotia $(\sim 2,100$ sclerotia) of $S$. minor were distributed evenly on the surface of each 7.6-m-long plot between the rows of lettuce, then incorporated into the top 5-cm layer of soil. For plots inoculated with $S$. sclerotiorum, $200 \mathrm{~cm}^{3}$ of the dried mixture of sclerotia and infested barley grain ( $\sim 800$ sclerotia) were distributed on each plot. Fungicide treatments were applied to the entire surface of treated beds and lettuce plants the day after inoculum distribution and again 2 weeks later with a tractor-mounted boom sprayer that delivered 468 liters/ha at $689 \mathrm{kPa}$ to nozzles spaced $30 \mathrm{~cm}$ apart. Treatments were replicated five times in 1999 and four times in 2000 and 2001 in a randomized complete block design, with each replicate consisting of $7.6 \mathrm{~m}$ of double-row bed. Treated beds of lettuce were separated by single untreated beds to minimize spray drift among plots. Final disease incidence was evaluated by recording the number of collapsed lettuce plants at crop maturity, which occurred on 19 March, 25 February, and 14 March in 1999, 2000, and 2001, respectively.

Analysis of data. Analysis of variance and mean separation tests were used where appropriate. Because the chemical rates in Figure 1 are quantitative values, 95\% confidence intervals were used to compare treatment means. Means that did not overlap at the $95 \%$ confidence interval were considered significantly different (6). Data from repeated field trials were combined for analysis since variance among trials was homogeneous according to Bartlett's test. Significant differences among main effects were determined by analysis of variance, and treatment means were separated according to the Duncan-Waller $k$ ratio (LSD) test. Data were processed using SPSS statistical package (SPSS Inc., Chicago, IL).

\section{RESULTS}

Growth from mycelial disks. At a concentration of $0.001 \mu \mathrm{g} / \mathrm{ml}$, inhibition of mycelial growth of $S$. minor among tested fungicides ranged from 4 to $20 \%$ (Fig. 1A). At $0.01 \mu \mathrm{g} / \mathrm{ml}$, fludioxonil and fluazinam suppressed mycelial growth of the pathogen from 82 to $84 \%$, whereas the activity of boscalid, fenhexamid, and vinclozolin ranged from 1 to $16 \%$. At a rate of

Table 1. Relative efficacy of fungicides for control of lettuce drop caused by Sclerotinia minor and S. sclerotiorum

\begin{tabular}{lllrcr}
\hline & \multirow{2}{*}{$\begin{array}{c}\text { Product name } \\
\text { and formulation }\end{array}$} & \multicolumn{1}{c}{ Source } & Rate (g a.i./ha) & S. minor & S. sclerotiorum \\
\cline { 3 - 6 } Common name & Omega 85DF & ISK Biosciences, Mentor, OH & 561 & $60.5 \mathrm{~b} *$ & $43.8 \mathrm{bc} *$ \\
Fluazinam & Endura 50WG & BASF Corp., Research Triangle Park, NC & 561 & $55.5 \mathrm{~b} *$ & $30.4 \mathrm{~b} *$ \\
Foscalid & Medallion 50WP & Syngenta Crop Protection, Inc., Greensboro, NC & 202 & $37.4 \mathrm{a}$ & $47.2 \mathrm{c}$ \\
Vinclozolin & Ronilan 50WP & BASF Corp., Research Triangle Park, NC & 1,122 & $34.9 \mathrm{a}$ & $52.2 \mathrm{c}$ \\
Fenhexamid & Elevate 50WDG & Arvesta Corp., San Francisco, CA & 842 & $27.3 \mathrm{a}$ \\
\hline
\end{tabular}

${ }^{z}$ Percent disease control compared with untreated plants. Each value is the mean of 13 replicate plots from three different field trials. Numbers in each column followed by a different letter are significantly different $(P=0.01)$ according to the Duncan-Waller $k$-ratio least significant difference (LSD) test. Values within the same row followed by an asterisk $(*)$ are significantly different $(P=0.01)$ from each other as well. 
$0.1 \mu \mathrm{g} / \mathrm{ml}$, inhibition of mycelial growth of S. minor ranged from 70 to $98 \%$ for all tested fungicides except vinclozolin (Fig. 1A). At $1.0 \mu \mathrm{g} / \mathrm{ml}$, suppression of growth for this fungus was 98 to $100 \%$ for fludioxonil, fluazinam, fenhexamid, and vinclozolin; however, a significantly lower level of $87 \%$ was achieved by boscalid at the same rate.

Mycelial growth of S. sclerotiorum was not affected by any of the tested compounds at a rate of $0.001 \mu \mathrm{g} / \mathrm{ml}$ (Fig. 1B). Growth of the pathogen was reduced $78 \%$ by fluazinam at $0.01 \mu \mathrm{g} / \mathrm{ml}$, whereas growth suppression in the presence of boscalid, fludioxonil, fenhexamid, and vinclozolin at the same rate was significantly less (0 to $12 \%)$. At $0.1 \mu \mathrm{g} / \mathrm{ml}$, mycelial growth of $S$. sclerotiorum was suppressed from 95 to $99 \%$ by fludioxonil and fluazinam, significantly less (40 to 47\%) by boscalid and fenhexamid, and not at all by vinclozolin (Fig. 1B). At a rate of 1.0 $\mu \mathrm{g} / \mathrm{ml}$, inhibition of growth of this fungus ranged from 98 to $100 \%$ for fludioxonil, fluazinam, fenhexamid, and vinclozolin, whereas reduction of growth by boscalid was significantly less at $77 \%$.
Growth from sclerotia. Inhibition of mycelial growth from sclerotia of $S$. minor and S. sclerotiorum ranged from 90 to $97 \%$ in the presence of fludioxonil and fluazinam at a rate of $0.1 \mu \mathrm{g} / \mathrm{ml}$ and was significantly greater than values ranging from 0 to $71 \%$ recorded for boscalid, fenhexamid, and vinclozolin (Fig. 1C and D). At 1.0 $\mu \mathrm{g} / \mathrm{ml}$, all tested fungicides suppressed growth from sclerotia of $S$. minor from 98 to $100 \%$. At the same rate, fenhexamid, fludioxonil, fluazinam, and vinclozolin inhibited mycelial growth from sclerotia of S. sclerotiorum from 90 to $96 \%$. Reduction of growth from sclerotia of this pathogen at $1.0 \mu \mathrm{g} / \mathrm{ml}$ by boscalid $(76 \%)$ was significantly less than values recorded for fludioxonil, fluazinam, and vinclozolin (Fig. 1D).

Field experiments. The results from three field trials are summarized in Table 1. In plots infested with $S$. minor, fluazinam and boscalid provided the highest level of disease control (60.5 and 55.5\%, respectively). In comparison, a significantly lower level of performance was observed in plots infested with the same pathogen and treated with fludioxonil, vinclozolin, and fenhexamid (37.4, 34.9, and $27.3 \%$ reduction in disease, respectively). For plots containing $S$. sclerotiorum, the highest degree of disease suppression occurred in the presence of vinclozolin, fludioxonil, and fluazinam, with values of $52.2,47.2$, and $43.8 \%$, respectively (Table 1). On the other hand, the least effective compound against $S$. sclerotiorum was fenhexamid, which reduced the number of diseased plants by $13.9 \%$ compared with untreated plants. Boscalid and fluazinam were more effective against lettuce drop caused by $S$. minor than against disease caused by $S$. sclerotiorum.

\section{DISCUSSION}

The major value of any chemical compound as a disease control agent ultimately depends on the mode of action of the molecule at the physiological level on one or more components of the life cycle of the pathogen. Eruptive germination of sclerotia followed by mycelial growth occurs when $S$. minor and S. sclerotiorum initiate disease in Arizona lettuce fields. Suppression of these activities should reduce the capacity of these pathogens to cause dis-
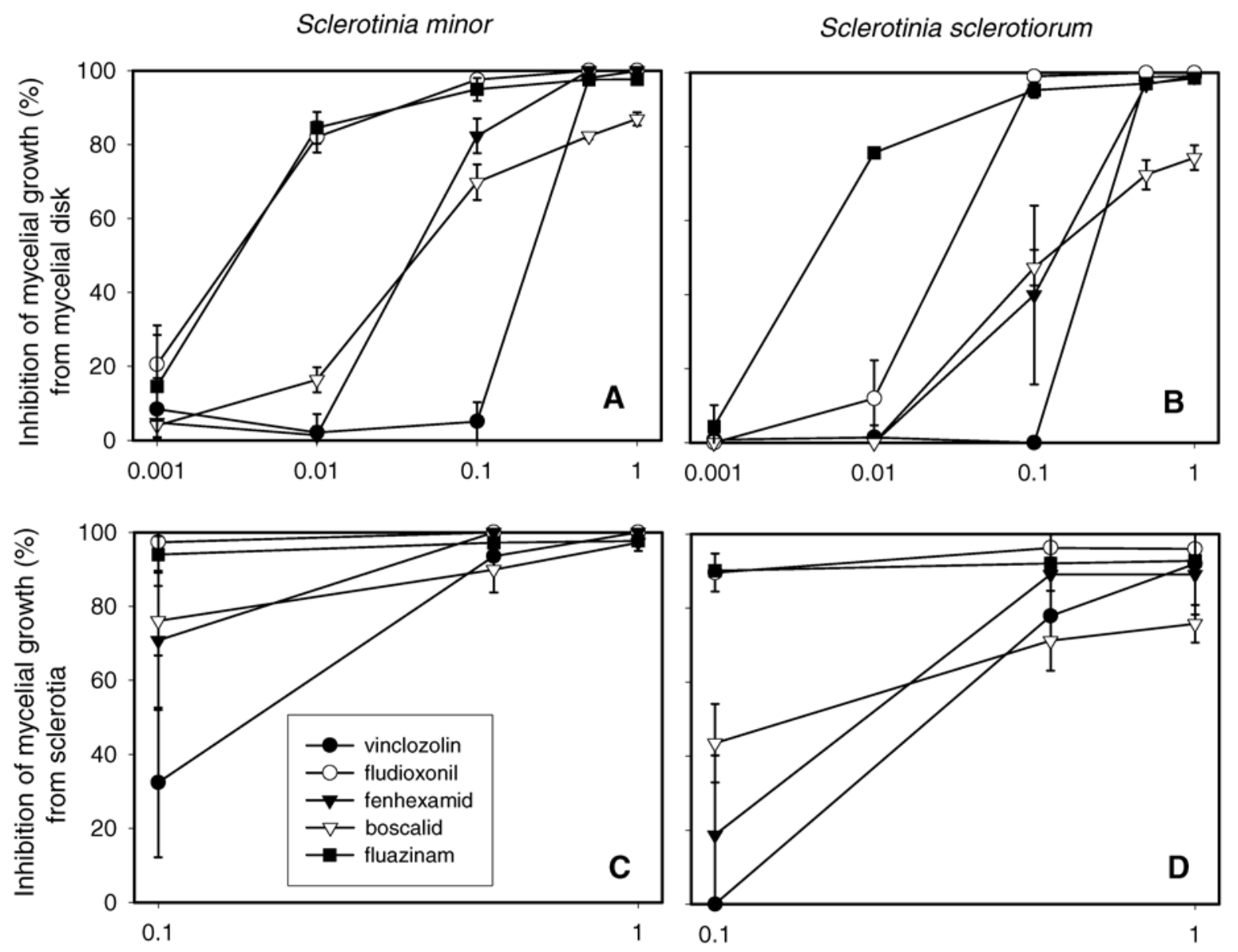

Fungicide concentration ( $\mu \mathrm{g}$ a.i. $/ \mathrm{ml})$

Fig. 1. Influence of dose of boscalid, fenhexamid, fluazinam, fludioxonil, and vinclozolin in potato dextrose agar medium in petri dishes on inhibition of mycelial growth from mycelial disks or sclerotia of Sclerotinia minor and S. sclerotiorum after a 3- to 5-day incubation period at $20^{\circ} \mathrm{C}$ in darkness. Each value is the mean of 8 or 10 replicate mycelial disks or sclerotia, respectively, from two runs of each experiment. Vertical bars for each data point are $95 \%$ confidence intervals. 
ease in the field. Laboratory studies defined the concentrations of each tested chemistry required to significantly inhibit mycelial growth of $S$. minor and S. sclerotiorum. At $0.001 \mu \mathrm{g} / \mathrm{ml}$, none of the tested fungicides had an appreciable effect on mycelial growth of $S$. minor or $S$. sclerotiorum, whereas, at $1.0 \mu \mathrm{g} / \mathrm{ml}$, all tested fungicides reduced mycelial growth of $S$. minor and $S$. sclerotiorum from 87 to $100 \%$ and 77 to $100 \%$, respectively.

In the field trials, each chemistry was applied at a much higher concentration than that tested in vitro, including boscalid at $1,200 \mu \mathrm{g} / \mathrm{ml}$, fenhexamid at $1,800 \mu \mathrm{g} / \mathrm{ml}$, fluazinam at $1,200 \mu \mathrm{g} / \mathrm{ml}$, fludioxonil at $430 \mu \mathrm{g} / \mathrm{ml}$, and vinclozolin at $2,400 \mu \mathrm{g} / \mathrm{ml}$ of spray solution. However, with an application rate of 468 liters of spray solution per hectare, the actual amount of fungicide applied on a soil surface area basis included boscalid at 5.6 $\mu \mathrm{g} / \mathrm{cm}^{2}$, fenhexamid at $8.4 \mu \mathrm{g} / \mathrm{cm}^{2}$, fluazinam at $5.6 \mu \mathrm{g} / \mathrm{cm}^{2}$, fludioxonil at 2.0 $\mu \mathrm{g} / \mathrm{cm}^{2}$, and vinclozolin at $11.2 \mu \mathrm{g} / \mathrm{cm}^{2}$. Movement into the soil profile would reduce the concentration of each fungicide further. At these concentrations, significant differences were noted in field performance among some fungicides. For plots infested with $S$. minor, the efficacy of boscalid and fluazinam was superior to that of fenhexamid, fludioxonil, and vinclozolin, whereas in plots infested with $S$. sclerotiorum, the highest levels of disease control were provided by fluazinam, fludioxonil, and vinclozolin.

The relative sensitivity of mycelial growth of $S$. minor and $S$. sclerotiorum to tested active ingredients demonstrated in laboratory evaluations did not have consistent predictive value with respect to performance of these fungicides in the field to control lettuce drop. Similar findings were reported in other studies $(10,15)$. There are several likely reasons for this disparity between activity in laboratory studies and efficacy in the field. Although the initial concentration of the spray solution was from 430 to 2,400 times greater than the highest rate evaluated in vitro, the final concentration of active ingredient in the field is affected by many factors. The laboratory tests only assessed the interaction of the pathogen with each chemistry, whereas disease control studies encompassed the interaction of the fungicide, pathogen, and host, including the effect of the environment in which the host is living and where disease development oc- curs. For the in vitro studies, each active ingredient was added to agar, which was maintained in the dark at a temperature of $20^{\circ} \mathrm{C}$ for no longer than 5 days. In contrast, when applied in the field to soil and lettuce seedlings, each active ingredient was subjected to a hostile environment in which activity must be maintained from application to crop maturity, which in the case of lettuce can be as long as 60 days.

The effective life of any active ingredient in the field is determined by the interaction of several different processes, which include but are not limited to hydrolytic and photochemical breakdown, microbial conversion and decomposition, and sorption or movement of the active ingredient and its metabolites (1). The processes governing breakdown of an active ingredient depend on its specific properties, such as water solubility, vapor pressure, polarity, structural properties, and so on. For example, fenhexamid is characterized by rapid breakdown, conversion, and mineralization in soil, with a half-life of less than $24 \mathrm{~h}$ (1). This rapid destruction in soil could explain the difference between the poor performance observed in the field for control of lettuce drop compared with the high activity noted in mycelial growth inhibition studies conducted in the laboratory as well as performance in the field to control white mold on a Brussels sprouts seed crop (5). Although the laboratory studies did not consistently predict the performance of fungicides in the field, these in vitro experiments established baseline sensitivity values in this fungal population that has not been previously exposed to these particular fungicides. In fungicide resistance management, baseline sensitivity data are critical for assessment of development of insensitivity within field populations of $S$. minor and S. sclerotiorum.

Compared with untreated plots, the highest reductions of lettuce drop achieved in these field trials were 60 and $52 \%$ in plots infested with $S$. minor and $S$. sclerotiorum, respectively. Similar results have been observed in earlier fungicide evaluations (10). Greater reductions in the incidence of Sclerotinia lettuce drop probably will require an integrated disease management approach, employing useful cultural control methods such as deep-plowing to bury sclerotia and crop rotations with nonhosts such as small grains, with chemical control as but one component.
LITERATURE CITED

1. Anderson, C., Brumhard, B., Ditgens, K., and Reiner, H. 1999. Metabolism of fenhexamid (KBR 2738) in plants, animals, and the environment. Pflanzenschutz-Nachr. Bayer 52:227251.

2. Anonymous. 1985. Integrated pest management for cole crops and lettuce. University of California I.P.M. Project. Publ. 3307.

3. Brown, J. G., and Butler, D. 1936. Sclerotiniose in lettuce in Arizona. Pages 475-506 in: Univ. Ariz. Agric. Exp. Stn. Bull. 63.

4. Dillard, H. R., Cobb, A. C., Amsel, N. A., Spratley, T. M., and Witt, E. P. 2003. Evaluation of foliar sprays for control of white and gray mold in snap beans in Geneva, NY, 2002. Fungic. Nematicide Tests 58:VO13.

5. du Toit, L. J., and Derie, M. L. 2001. Evaluation of fungicides for control of white mold and ringspot, 2000-2001. Fungic. Nematicide Tests 57:VO13.

6. Glantz, S. A. 2002. Primer of Biostatistics. 5th ed. McGraw-Hill Book Co., New York.

7. Hanson, B. K., and Lamey, H. A. 2001. Evaluation of foliar fungicides on canola for control of Sclerotinia stem rot, 2000. Fungic. Nematicide Tests 56:FC1.

8. Hao, J. J., Subbarao, K. V., and Duniway, J. M 2003. Germination of Sclerotinia minor and $S$ sclerotiorum sclerotia under various soil moisture and temperature combinations. Phytopathology 93:443-450.

9. Imolehin, E. D., and Grogan, R. G. 1980 Factors affecting survival of sclerotia, and effects of inoculum density, relative position, and distance of sclerotia from the host on infection of lettuce by Sclerotinia minor. Phytopathology 70:1162-1167.

10. Matheron, M. E., and Matejka, J. C. 1989. In vitro and field comparison of six new fungicides with iprodione and vinclozolin for control of leaf drop of lettuce caused by Sclerotinia sclerotiorum. Plant Dis. 73:727-730.

11. Mueller, D. S., Hartman, G. L., and Pedersen, W. L. 1999. Development of sclerotia and apothecia of Sclerotinia sclerotiorum from infected soybean seed and its control by fungicide seed treatment. Plant Dis. 83:1113-1115.

12. Patterson, C. L., and Grogan, R. G. 1985. Differences in epidemiology and control of lettuce drop caused by Sclerotinia minor and $S$. sclerotiorum. Plant Dis. 69:766-770.

13. Reilly, C. C., and Lamoureux, G. L. 1981. The effects of the fungicide iprodione on the mycelium of Sclerotinia sclerotiorum. Phytopathology 71:722-727.

14. Ryley, M. J., Kyel, N. A., and Tatnell, J. R. 2000. Evaluation of fungicides for the management of sclerotinia blight of peanut. Aust. J. Agric. Res. 51:917-924.

15. Smith, F. D., Phipps, P. M., and Stipes, R. J. 1991. Agar plate, soil plate, and field evaluation of fluazinam and other fungicides for control of Sclerotinia minor on peanut. Plant Dis. 75:1138-1143.

16. Springer, J. K., and Johnston, S. A. 1982 Fungicides for lettuce drop. Plant Dis. 66:281.

17. Subbarao, K. V. 1997. Drop. Pages 19-21 in: Compendium of Lettuce Diseases. R. M. Davis, K. V. Subbarao, R. N. Raid, and E. A Kurtz, eds. American Phytopathological Society, St. Paul, MN. 